\title{
Education Research: Effect of the COVID-19 pandemic on neurology trainees in Italy
}

\section{A resident-driven survey}

Elena Abati, MD,* and Gianluca Costamagna, MD*

Neurology ${ }^{\circledR}$ 2020;95:1061-1066. doi:10.1212/WNL.0000000000010878

\section{Abstract}

\section{Objective}

To assess the effect of the coronavirus disease 2019 (COVID-19) outbreak on neurology resident training in Italy.

\section{Method}

We created a web-based survey regarding changes in clinical, research, and educational activity of neurology trainees in Italy during the COVID-19 pandemic and the preventive measures undertaken by local institutions to reduce the risk of contagion.

\section{Results}

Seventy-nine residents working in Italy completed the survey. A total of $87.3 \%$ of trainees reported a substantial reduction in their neurologic duties since COVID-19 appeared in Italy, and $17.8 \%$ were also recruited or volunteered for COVID-19-dedicated wards. Likewise, more than $60 \%$ of trainees experienced a reduction or interruption in research activity. As regards the perceived effect of the COVID-19 outbreak on their neurologic training, almost $70 \%$ of surveyed trainees believe that the COVID-19 pandemic had or will have a negative effect on their formation as neurologists, for different reasons. Furthermore, trainees reported a consistent exposure (69.6\%) to confirmed positive COVID-19 cases at work, with divergent surveillance and preventive measures taken by local institutions.

\section{Conclusions}

Overall, the survey shows that the COVID-19 pandemic in Italy has had a subjective negative effect on neurology residents on didactics, clinical, and research training as well as training abroad. The COVID-19 outbreak poses many challenges to academic institutions and training programs, and addressing these issues promptly is crucial to ensure continued quality of trainees' neurologic education. Sharing solutions and ideas among the international neurologic community might help neurology training programs worldwide to better counteract these problems.

\author{
Correspondence \\ Dr. Abati \\ elenafrancesca.abati@ \\ gmail.com
}

\section{MORE ONLINE}

COVID-19 Resources

For the latest articles, invited commentaries, and blogs from physicians around the world

NPub.org/COVID19 
Since its appearance at the end of 2019, the novel coronavirus severe acute respiratory syndrome coronavirus 2 (SARS-CoV2) has spread rapidly throughout the world, forcing national health systems and global health institutions to respond quickly to this challenge in order to control the dramatic rise in infected people needing hospitalization and respiratory support. Italy was the first European country to be hit by sustained local transmission of SARS-CoV-2, and to date it has the third highest number of confirmed cases worldwide (over 183,000 confirmed cases as of this writing). ${ }^{1}$ In this setting, the majority of hospitals had to shift resources from nonurgent to urgent care, restructuring parts of their facilities to host intensive and sub-intensive care beds, converting specialized units into coronavirus disease 2019 (COVID-19)-dedicated wards. In light of these changes, highly specialized physicians, such as neurologists, faced major changes in their activity, ranging from the reduction in outpatient services to deployment in internal medicine or COVID-19 wards. ${ }^{2-6}$ In this emergency context, neurology residents are no exception.

Many neurology training programs are faced with pandemicrelated challenges, such as the quick adoption of virtual learning strategies, the need for ensuring residents' safety, and the shift to telemedicine. Adaptive solutions have been implemented in many neurology residency programs, but this pandemic will likely have a long-lasting effect on the education of neurology trainees. The potential effects on neurologic education, daily clinical practice, and research training are unclear. In addition, neurology residents might have been reassigned to COVID-19 wards, but their involvement may vary among different countries. We created this survey to address these unanswered questions, to assess the needs and feelings of our fellow residents in this moment, and to identify critical issues connected with the COVID-19 effect on neurologic training in Italy.

\section{Methods}

An online-based survey was distributed among a sample of 110 trainees enrolled in an adult neurology residency program in Italy between April 13 and April 17, 2020. The survey was created with Google Forms and sent to neurology residents via e-mail by contacting local trainees' representatives (role similar to chief resident) and using residency programs' mailing lists, via a group for neurology residents on a social media. A limit of one response per participant was ensured. The anonymity of results was guaranteed to protect participants. No compensation was offered. A total of 79 complete questionnaires (where all requested answers were provided) from 13 Italian regions were included in the analysis. The study was reviewed and approved by the institutional review board.

\section{Survey}

The survey was divided into 6 sections:

1. Demographic questions: this section included information about participants' age and location (region and city) of the Residency Program.
2. Clinical training questions: this section assessed clinical duties of trainees before and after the pandemic.

3. Research training questions: this section asked whether and how the pandemic affected the research work of trainees.

4. Training abroad questions: this section assessed whether the trainee was working/studying abroad before the pandemic and pandemic's effects on hosting structure activities and permanence abroad.

5. Didactics questions: this section investigated the effects of the pandemic on education curricula (e.g., morning reports, noon conferences, clinical grand rounds) and the residents' perception of the impact of the pandemic on clinical and neurologic knowledge.

6. Contagion prevention and surveillance questions: this section asked about contact with patients with confirmed COVID-19, preventive measures taken by employing institution, adequate supply of personal protective equipment (PPE), and special training received by residents in COVID-19 wards.

The survey is available in the supplementary material from Zenodo (doi.org/10.5281/zenodo.3958033).

\section{Results}

\section{Demographics}

Seventy-nine neurology residents out of 120 completed the survey, with a $65.8 \%$ response rate. The mean age \pm SD of respondents was $27.8 \pm 1.2$ years. Median age was 28 years (range 26-31, interquartile range 2). Responders are distributed in 13 out of 20 Italian regions (figure e1, appendix, doi.org/10.5281/zenodo.3958033). Among them, 50.6\% work in Lombardy, the worst-hit region, with more than 65,000 confirmed cases so far (see supplementary material, available from Zenodo, for additional demographic results, doi.org/10.5281/zenodo.3958033).

\section{Effect of COVID-19 on clinical practice}

When COVID-19 first appeared in Italy, 62\% of the surveyed population was working in an inpatient clinic, $30.4 \%$ in day hospital, outpatient clinic, or neurophysiology or neurosonology services, $3.8 \%$ in full-time research activity, and 3.8\% were doing clinical or research training abroad (figure 1 ; interactive figure 1 [links.lww.com/WNL/B237]). The effects of the pandemic on clinical activity were different (figure 1 ; interactive figure 1 [links.lww.com/WNL/B237]), but $87.3 \%$ of trainees reported a substantial reduction in their neurologic duties. A total of $17.8 \%$ were also recruited or volunteered for non-neurologic or COVID-19 wards. Four trainees temporarily interrupted their neurologic training and were hired as nonspecialist physicians in COVID-19 units.

\section{Effect of COVID-19 on research activities and training abroad}

The majority of trainees doing research reported that research activity was partially $(39.4 \%$; $=26)$ or totally $(36.4 \% ; n=$ 


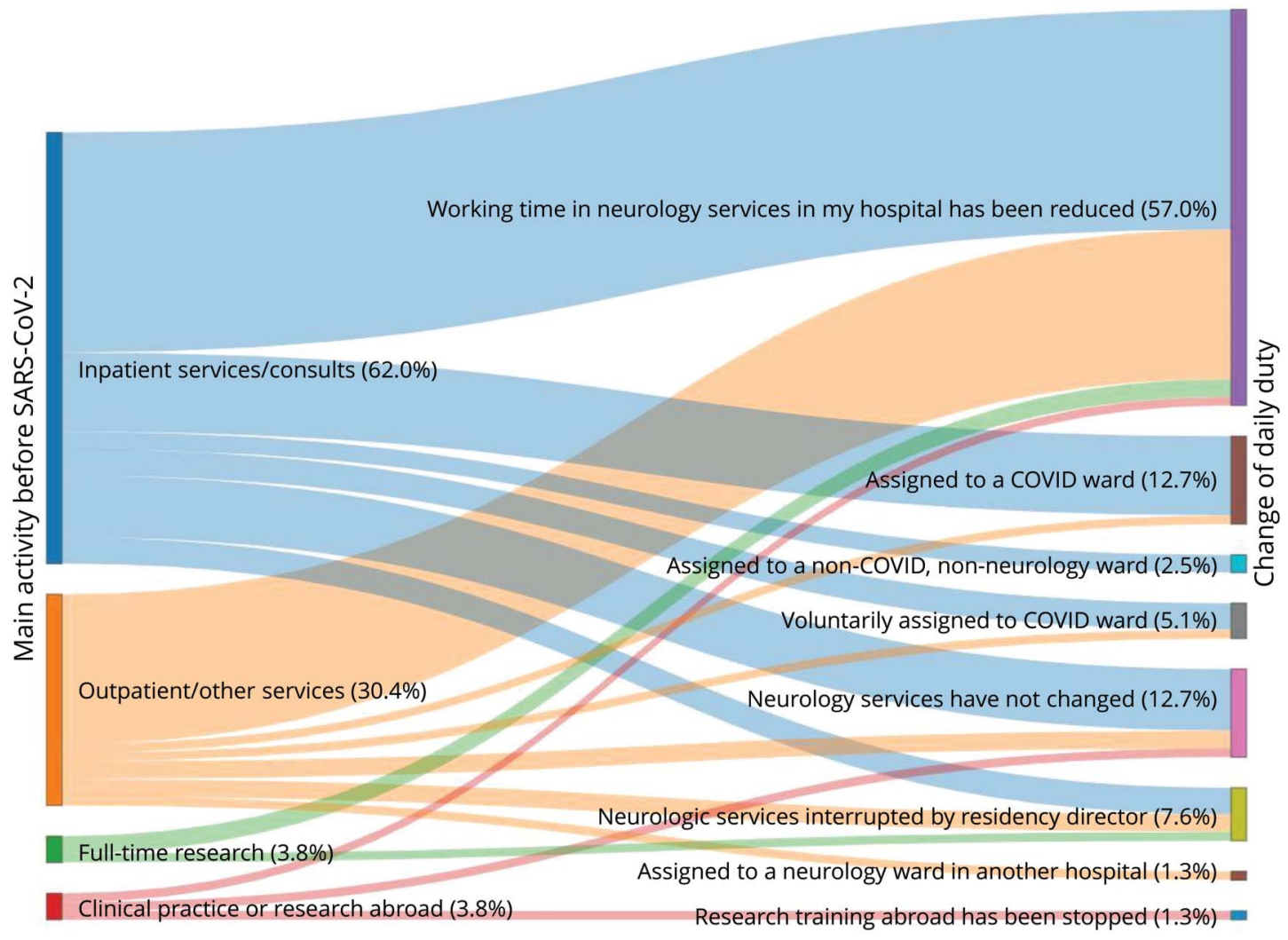

Sankey diagram displays the change in residents' daily duties as a flux. The left side shows the activity each responding resident was performing when the first case of COVID-19 local transmission was reported in Italy (February 21, 2020); the right side shows the change in daily activity for every specific respondent. The lines connect specific respondents. The most frequent changes in trainees' activity include reduced working time in neurology services (57\%) and assignment to COVID-19 (12.7\%). An interactive version of this figure is available online (links.Iww.com/WNL/B237). SARS-CoV-2 = severe acute respiratory syndrome coronavirus 2 .

24) interrupted (figure 2A). Reasons for the reduction or suspension of research activity were the partial or total closure of research laboratories, relocation of support/research personnel to other services, unavailability of neurophysiologic or imaging instrumentations, temporary suspension of clinical trials, impossibility to enroll new patients, and lack of time.

A smaller fraction of trainees reported that research activity has not changed or that it increased $(24.5 \% ; n=16)$ (figure $2 \mathrm{~A})$.

Three trainees (3.8\% of the total) reported being abroad for clinical or research training at the time of the COVID-19 outbreak. One trainee remained at the hosting Institution, although activity was partially suspended; 1 trainee kept working on previously started projects remotely; 1 trainee chose to return to Italy.

\section{Effect of COVID-19 on neurologic education}

Regarding educational curricula, $51.9 \%$ of responders $(n=41)$ from 10 different regions-29.1\% $(\mathrm{n}=23)$ from Lombardy-stated that these activities had been suspended due to the pandemic. Conversely, 30.4\% $(n=24)$ reported that educational activities were carried out on virtual platforms (figure 2B). When asked about their perception of the effect of the COVID-19 outbreak on their general formation as clinicians, $48.1 \%$ of responders $(n=38)$ declared that it had or will have a negative effect, while $34.2 \%(\mathrm{n}=27)$ believed it had or will have a positive effect (figure 2C). Reasons for a positive answer were that COVID-19 stimulated personal study and helped them foster their knowledge and ability to care for patients with respiratory symptoms and other internal problems. Those who reported a negative effect said that the pandemic impaired their professional development as clinicians and neurologists, although some participants recognized an improvement in their knowledge regarding acute respiratory syndromes. A total of $69.6 \%$ of surveyed trainees $(n=55)$ believed that the COVID-19 pandemic had or will have a negative effect on their formation as neurologists (figure 2D). Reasons for this answer were different and included the forced closure of outpatient services such as neurophysiology and neurosonology and the interruption of rotations and research activity. In contrast, $11.4 \%(\mathrm{n}=9)$ believed the pandemic had a positive effect on their neurologic education, because of the possibility to gain knowledge regarding COVID-19 neurologic manifestations, to expand and deepen their neurologic background due to an increase in study time, and, in 1 case, to care for an increased number of patients with stroke. 
Figure 2 Effect of the coronavirus disease 2019 (COVID-19) pandemic on research work and neurologic education of neurology trainees in Italy

A. How has your research activity in neurology changed during the SARS-CoV-2 pandemic? (66 responses)

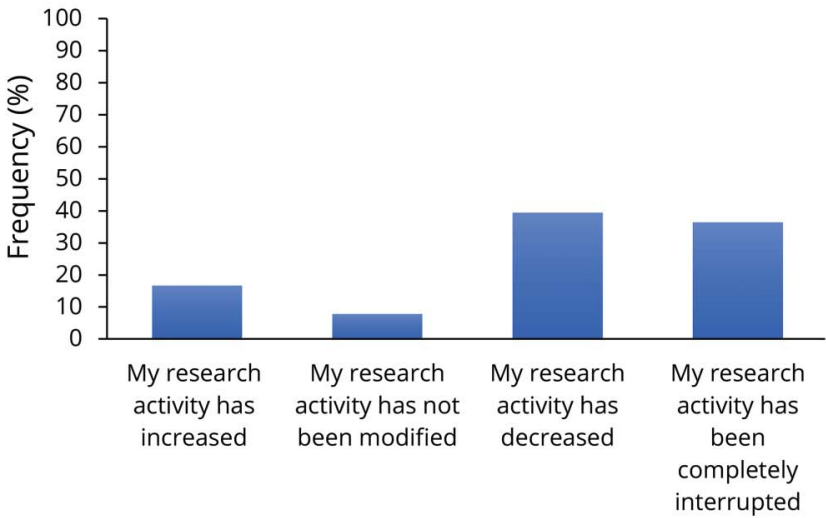

C. Do you think that the SARS-CoV-2 pandemic will have an impact on your clinical training? (79 responses)

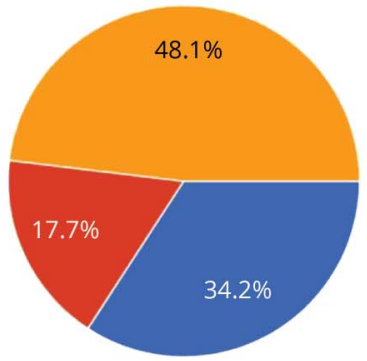

B. How has your didactic curriculum changed during the SARS-CoV-2 pandemic? (79 responses)

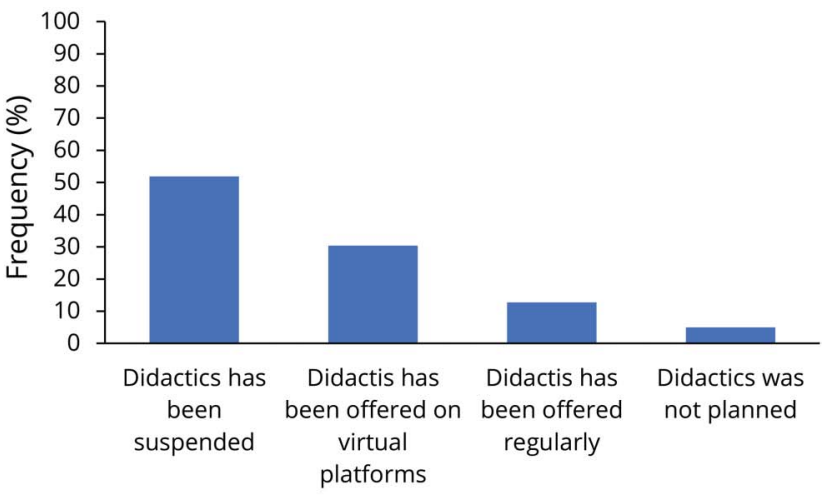

D. Do you think that the SARS-CoV-2 pandemic will have an impact on your neurology training? (79 responses)

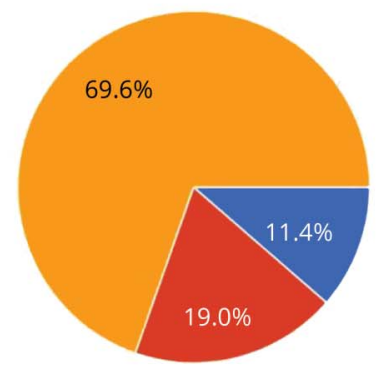

A positive impact

No impact at all

A negative impact

(A, B) Bar graphs show how research activity and didactics changed during the pandemic. (A) Research activity decreased (39.4\%) or stopped (36.4\%) for most respondents. (B) Changes in didactics included suspension of activities (51.9\%) or use of virtual platforms (30.4\%). (C, D) Pie charts present the perceived effect of the pandemic on general clinical and neurologic education. A negative effect is reported on both (C) general clinical education (48.1\%) and (D) neurology training (69.6\%). SARS-CoV-2 = severe acute respiratory syndrome coronavirus 2.

\section{Contagion prevention, training, and surveillance}

Among surveyed residents, $69.6 \%(\mathrm{n}=55)$ reported contact with confirmed COVID-19 cases (patients or colleagues). As a preventative measure, $10.6 \%$ were asked to start precautionary home isolation regardless of the presence of symptoms, $42.9 \%$ underwent nasopharyngeal swab to define the need for isolation, 3.6\% underwent serologic analyses for the presence of SARS-CoV-2 IgG/IgM, and $30.4 \%$ were advised to self-isolate only in case of appearance of COVID-19-related symptoms (figure e2, available at doi.org/10.5281/zenodo.3958033). In $28.6 \%$ of cases, the hospital/hosting structure did not take any precautionary measures. A total of $92.4 \%$ reported that, in their hospitals, at-risk residents underwent surveillance nasopharyngeal swabs at regular intervals.

As regards the availability of PPE, an adequate supply of PPE was reported by $41.8 \%(n=33)$. A total of $39.2 \%(n=31)$ said PPE was available for them only on some occasions, and 5.1\% $(n=4)$ claimed that their structure did not provide them with adequate PPE. Among those working in a COVID-19 ward (40 trainees), 14 underwent training on patient management or the use of ventilation devices (virtually or in the hospital), while 26 did not undergo any training and, in half of the cases, studied the topic on their own (figure e3, available at doi.org/ 10.5281/zenodo.3958033).

\section{Discussion}

We found that the COVID-19 pandemic in Italy had an overall subjective negative effect on neurology residents on didactics, clinical, and research training as well as training abroad. In addition, we highlighted consistent exposure for trainees to confirmed positive COVID-19 cases at work, with divergent surveillance and preventive measures taken by local institutions.

We aimed to depict a larger picture of the pandemic's effect on Italian neurology trainees, although we are aware of the profound regional differences that may be present in different training programs and the variable burden of COVID-19 among regions. Other limitations include the fact that most of the respondents work in Lombardy, one of the worst-hit areas 
worldwide, and that residents here may have had the highest degree of reorganization of health care workers and facilities. In addition, our survey reached only a fraction of neurology residents (a sample of 120 trainees), with a satisfying response rate among them (65.8\%). Surveys are a simple and quick method to gather different opinions without the need for inperson meetings, and they have already been used to assess the satisfaction and needs of neurology trainees in the past. They also carry the potential to reach a large population and collect large amounts of information. ${ }^{7}$ The downside is the risk for a low response rate, which might affect the validity of the study. In this regard, previous studies have outlined strategies for increasing response rate, which, in case of electronic surveys, include nonmonetary incentives, personalized and short questionnaires, offer of results, and a careful choice of words in the accompanying letter. ${ }^{8}$ In our case, we could not offer incentives as we did not receive funding for this study, but we tried to keep the questionnaire short and we offered to share results through peer-reviewed publication.

The COVID-19 outbreak poses many challenges to our academic institutions and training programs worldwide. Addressing these issues with an adaptive and creative spirit is crucial to ensure the quality of trainees' education while caring for patients.

A critical issue appears to be the reduction in clinical neurologic activity and the interruption of specialized training (e.g., neurophysiology, neurosonology). It is unlikely that it will be possible to counteract this problem in the immediate future, but training programs should direct their efforts towards the optimal reorganization of the neurologic activity of trainees as soon as the emergency subsides. Temporarily deploying trainees in hub hospitals with greater numbers of neurologic inpatients could also be a potential solution, where practicable. Increased adoption of telemedicine for outpatient visits could also allow this clinical activity, without concerns related to PPE availability. Telemedicine has been already exploited in other neurology training programs in response to the pandemic, ${ }^{3-5}$ giving trainees the possibility to actively care for neurologic patients without safety hazards. Telemedicine is a well-studied option and it is likely to grow in the future. ${ }^{9}$ It carries the advantages of improving access and reducing travel expenses, thus enabling distant or low-income patients to access neurologic care. ${ }^{9}$ However, it may not be a viable option for those who do not have access to a computer or smartphone or a reliable Internet connection. In addition, it may not be technically feasible in all hospitals or other health care facilities. Not every neurologic patient may be reliably evaluated via telemedicine; for instance, it would be difficult to assess the strength of patients with neuromuscular disorders. We need to develop and validate standardized tasks or scales to administer during the visit. Previous studies showed good interrater reliability among neurologic examination for stroke, dementia, and neuropathy evaluated remotely, although further research is necessary. ${ }^{10-13}$

The survey evidenced that many trainees volunteered for COVID-19 wards, thus showing adaptability. Indeed, many trainees believe that the pandemic gave them the occasion to improve their general medical formation. This finding highlights the resilience of trainees in pursuing the best medical formation in extraordinary situations. Given the interest expressed by the residents regarding COVID-19-related formation (management of patients with respiratory symptoms, use of invasive and noninvasive ventilation devices, proper use of potential treatments), our proposal for neurology residency coordinators would be to provide educational material on this matter, especially to trainees who are directly involved in COVID-19 patient care.

As regards educational activity, virtual and remote learning offer great potential for both professors and residents. ${ }^{3,14,15}$ Only a third of surveyed trainees reported receiving virtual didactics in these weeks. The implementation of virtual learning, including online lessons, webinars, and creation of remote or web-based learning modules, is a viable option for training programs, as already demonstrated in other programs worldwide. ${ }^{3,4,14}$ Remote education was widely used before the COVID-19 pandemic, but the didactic curricula of many training programs in Italy were still based on inperson lessons. As outlined in previous studies, virtual learning represents a valuable option to reduce access barriers. ${ }^{16,17}$ In the case of neurology trainees, it may allow all trainees to participate in educational sessions without colliding with busy schedules and duty-hour restrictions. To this aim, asynchronous e-learning may be preferred. ${ }^{16}$ The main obstacles to the integration of e-learning into educational curricula identified in previous studies were lack of financial resources, inadequate technology, limited bandwidth, and lack of skills. ${ }^{16,18,19}$ Moreover, the absence of face-to-face teaching may also lead to disengagement and reduced teaching effectiveness. ${ }^{16}$ Solutions that have been proposed include user-friendly packages, increased funding to e-learning and technological devices, skills training, and the use of interactive e-learning methods. ${ }^{16,19}$ In the future, it would be interesting to better investigate e-learning effectiveness and limitations in neurology training programs with further studies. Education is an ever-changing matter, and tools such as virtual education and telemedicine, if properly developed, might become an integral part of the medical and neurologic education of the future.

Another imperative point for trainees, and all health care workers, is the availability of PPE and proper surveillance for at-risk personnel. Surveillance is a crucial public health issue because young health care workers represent an important source of infection. However, despite almost $70 \%$ of participants declaring that they were exposed to confirmed cases, responses of residency program coordinators and hospital boards were heterogeneous, and in $30 \%$ of cases no preventative measure was undertaken. The availability of PPE remains erratic in some structures. Nationwide PPE shortage and insufficient capacity to process specimens from suspected cases may have conditioned such problems. To minimize exposure and prevent PPE depletion, medical 
personnel directly interacting with patients should be reduced to the minimum necessary, as in other programs. ${ }^{3-5} \mathrm{~A}$ wide range of tasks can be performed by trainees in clean environments, such as paperwork and calls to family members. ${ }^{4,5}$ Rules regarding the use of PPE should be strictly followed, and ensuring safety and protection of trainees should be a priority.

The COVID-19 pandemic came unexpectedly, forcing the medical community to adapt to a rapidly changing scenario. Several neurology training programs already described their response to this pandemic, which included reducing the number of residents involved in inpatient and outpatient services, deploying some residents to intensive care units and COVID-19 medical wards, transitioning outpatient visits to a telemedicine model whenever possible, and enabling virtual education for trainees. ${ }^{3-6}$ With our survey, we highlighted some of the problems that arose in neurology residency programs in Italy, such as the reduction in clinical practice, the forced closure of specialist services, and the incomplete availability of virtual education and PPE. We propose solutions based on the experiences of other centers and on previous studies. These observations will remain relevant after the first phase of the pandemic has subsided as before the development of an effective vaccine it is likely that we will witness cyclic resurgence of COVID-19. We hope that sharing our results might help neurology residency programs coordinators identify effective responses to such issues.

\section{Acknowledgment}

The authors thank the trainees who participated in this survey and their professors; the community of Italian neurologists; and M. Maffioletti, MSc, and L. Cavallera, MSc, for their help with the interactive figures.

\section{Study funding}

No targeted funding reported.

\section{Disclosure}

The authors report no disclosures relevant to the manuscript. Go to Neurology.org/N for full disclosures.

\section{Appendix Authors}

\begin{tabular}{lll}
\hline Name & Location & Contribution \\
\hline $\begin{array}{l}\text { Elena Abati, } \\
\text { MD }\end{array}$ & $\begin{array}{l}\text { University } \\
\text { of Milan }\end{array}$ & $\begin{array}{l}\text { Study concept and design, analysis or } \\
\text { interpretation of data, drafting and } \\
\text { revising the manuscript, accepts } \\
\text { responsibility for conduct of research and } \\
\text { final approval, study supervision }\end{array}$ \\
\hline $\begin{array}{l}\text { Gianluca } \\
\text { Costamagna, }\end{array}$ & $\begin{array}{l}\text { University } \\
\text { of Milan }\end{array}$ & $\begin{array}{l}\text { Study concept and design, analysis or } \\
\text { interpretation of data, drafting and } \\
\text { revising the manuscript, accepts } \\
\text { responsibility for conduct of research and } \\
\text { final approval, study supervision }\end{array}$ \\
\hline
\end{tabular}

\section{References}

1. Dong E, Du H, Gardner L. An interactive web-based dashboard to track COVID-19 in real time. Lancet Infect Dis 2020;20:533-534.

2. Bersano A, Pantoni L. On being a neurologist in Italy at the time of the COVID-19 outbreak. Neurology 2020;94:905-906.

3. McArthur JC. The path forward: academic neurology responds to COVID-19. Ann Neurol 2020;87:789-793.

4. Agarwal S, Sabadia S, Abou-Fayssal N, Kurzweil A, Balcer LJ, Galetta SL. Training in neurology: flexibility and adaptability of a neurology training program at the epicenter of COVID-19. Neurology 2020;94:e2608-e2614.

5. Waldman G, Mayeux R, Claassen J, et al. Preparing a neurology department for SARSCoV-2 (COVID-19). Neurology 2020;94:886-891.

6. Leira EC, Russman AN, Biller J, et al. Preserving stroke care during the COVID-19 pandemic: potential issues and solutions. Neurology 2020;95:124-133.

7. Jones T, Baxter M, Khanduja V. A quick guide to survey research. Ann R Coll Surg Engl 2013;95:5.

8. Edwards PJ, Roberts I, Clarke MJ, et al. Methods to increase response to postal and electronic questionnaires. Cochrane Database Syst Rev 2009;3:MR000008.

9. Bloem BR, Dorsey ER, Okun MS. The coronavirus disease 2019 crisis as catalyst fo telemedicine for chronic neurological disorders. JAMA Neurol 2020;77:927-928.

10. Lott IT, Doran E, Walsh DM, Hill MA. Telemedicine, dementia and down syndrome: implications for Alzheimer disease. Alzheimers Dement 2006;2:179-184.

11. Wilson AM, Ong MK, Saliba D, Jamal NI. The veterans affairs neuropathy scale: a reliable, remote polyneuropathy exam. Front Neurol 2019;10:1050.

12. Awadallah M, Janssen F, Körber B, Breuer L, Scibor M, Handschu R. Telemedicine in general neurology: interrater reliability of clinical neurological examination via audiovisual telemedicine. Eur Neurol 2019;80:289-294.

13. LaMonte MP, Bahouth MN, Xiao Y, Hu P, Baquet CR, Mackenzie CF. Outcomes from a comprehensive stroke telemedicine program. Telemed J E Health 2008;14:339-344.

14. Pavitt S. Invited commentary: the overnight change of resident education. Neurology Blogs [online]. Available at: blogs.neurology.org/rf/invited-commentary-the-overnight-change-of-resident-education/. Accessed April 21, 2020.

15. Rakowsky S, Flashner BM, Doolin J, et al. Five questions for residency leadership in the time of COVID-19. Acad Med 2020;95:1152-1154.

16. Wittich CM, Agrawal A, Cook DA, et al. E-learning in graduate medical education: survey of residency program directors. BMC Med Educ 2017;17:144.

17. Sargeant JM. Medical education for rural areas: opportunities and challenges for information and communications technologies. J Postgrad Med 2005;51:301-307.

18. Childs S, Blenkinsopp E, Hall A, Walton G. Effective e-learning for health professionals and students: barriers and their solutions: a systematic review of the literature: findings from the HeXL project. Health Info Libr J 2005;22:20-32.

19. Walsh S, De Villiers MR, Golakai VK. Introducing an E-learning solution for medical education in Liberia. Ann Glob Health 2018;84:190-197.

\section{Missed the Fall Conference? It's Now Available On Demand!}

Even if you missed the 2020 AAN Fall Conference, you can still access the quality CME, expert faculty, and innovative science at your convenience with Fall Conference On Demand! Access now at AAN.com/20FC. 


\section{Neurology}

\section{Education Research: Effect of the COVID-19 pandemic on neurology trainees in Italy: A resident-driven survey Elena Abati and Gianluca Costamagna}

Neurology 2020;95;1061-1066 Published Online before print September 16, 2020

DOI 10.1212/WNL.0000000000010878

This information is current as of September 16, 2020

\section{Updated Information \&} Services

References

Subspecialty Collections

Permissions \& Licensing

Reprints including high resolution figures, can be found at: http://n.neurology.org/content/95/23/1061.full

This article cites 18 articles, 4 of which you can access for free at: http://n.neurology.org/content/95/23/1061.full\#ref-list-1

This article, along with others on similar topics, appears in the following collection(s):

Other Education

http://n.neurology.org/cgi/collection/other_education

Information about reproducing this article in parts (figures,tables) or in its entirety can be found online at:

http://www.neurology.org/about/about_the_journal\#permissions

Information about ordering reprints can be found online:

http://n.neurology.org/subscribers/advertise

Neurology ${ }^{\circledR}$ is the official journal of the American Academy of Neurology. Published continuously since 1951, it is now a weekly with 48 issues per year. Copyright () 2020 American Academy of Neurology. All rights reserved. Print ISSN: 0028-3878. Online ISSN: 1526-632X.

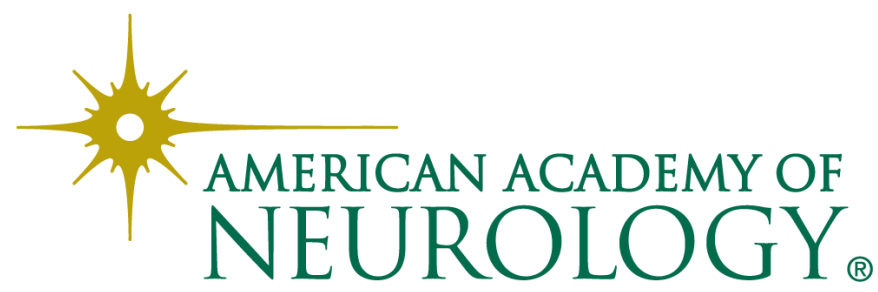

